\title{
From the Bronze Age to the Iron Age in Thailand: Applying the Heterarchical Approach
}

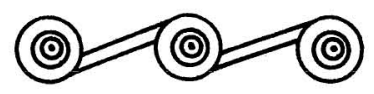

\author{
DOUGALD J. W. O'REILLY
}

THERE HAS, OF LATE, BEEN INCREASING interest in the social organization of prehistoric Southeast Asia (Bayard 1992; Higham and Thosarat 2000; O'Reilly 1999; White 1995; White and Pigott 1996). Most of this discussion has focused on Bronze Age Thailand, which is often perceived to follow an unusual trajectory of social development (Bronson 1979; White 1995). These authors have noted that Southeast Asia, especially Thailand, does not follow the same trajectory that other areas of the world did after the introduction of bronze. Recent excavations at Iron Age sites in northeast Thailand provide fascinating insight into social organization after 500 B.C. The evidence from these excavations lends support to the proposition that the sociopolitical climate during the Iron Age was considerably different from that of the Bronze Age (c. 1500-500 B.C.). It would appear that there was a shift in the organization of society, and hierarchies seem to have become entrenched. This is not a revelation: indeed, these differences are the foundation of the chronological division of Southeast Asia. The Bronze Age is subsumed by General period B and the Iron Age falls within General period C (Bayard 1984) (see Table 1). It should be noted that there is considerable disagreement over the dating of the Bronze Age in Thailand, which has polarized into those who support a long chronology (Bayard 1996; White 1982) and those who propose a short chronology (Higham 1994). It is the purpose of this paper to examine the social and political changes apparent in the archaeological record and to advance some possible causative factors for the perceived differences between General periods $B$ and $C$.

This paper explores the meaning of heterarchy and the application of this theoretical model to the Bronze Age of Southeast Asia. It examines current interpretations of the Iron Age social milieu. New evidence from recently excavated sites in northeast Thailand are also introduced. Models of social organization are evaluated considering this evidence, and alternative explanations are proposed for developments in Southeast Asia from the Bronze Age into the Iron Age.

\section{APPLYING THE HETERARCHICAL MODEL TO SOUTHEAST ASIA}

Definitive evidence of a hierarchical social structure has not been produced for sites ascribed to General period B in Thailand. The data from these sites, such as 
Table I. Chronological Models for Southeast Asia

\begin{tabular}{lll}
\hline PERIOD & \multicolumn{1}{c}{ BRONZE AGE } & \multicolumn{1}{c}{ IRON AGE } \\
\hline Long chronology & c. 1700 B.C. -500 B.c. & c. 500 B.C. \\
Short chronology & c. 1500 B.c. -500 B.C. & c. 500 B.C. \\
Period (after Bayard 1984) & General period B & General period C \\
\hline
\end{tabular}

Nong Nor, Khok Phanom Di, Ban Na Di, and Non Nok Tha, contain none of the hallmarks of highly ranked or stratified society (Bayard 1976; Higham and Bannanurag 1990; Higham and Kijngam 1984; Higham and Thosarat 1998), nor are there any differences in the number and form of artifacts in burials across age and sex categories (Wilen 1992:105). Some have argued that the lack of weaponry in graves may indicate a low incidence of intercommunity conflict during the Bronze Age (White 1982:48). Production seems to have occurred at the household level, including the mining of copper and bronze casting, both of which require significant expertise (Bennett 1988:133; Weiss 1992; White 1995:107; White and Pigott 1996:165). There is no evidence that large labor forces were marshaled or controlled by a central authority, nor is there any convincing evidence of restricted access to resources during the Bronze Age in Thailand (White 1995:107).

\section{Heterarchy}

The anomaly presented by General period B data has long been cited "for patterns which fail to fit anyone's models for normal sociocultural development" (Bronson 1979:321). The models described are those devised by Fried (1967), Sahlins (1958), and others (Friedman and Rowlands 1977; Service 1962). These theories, which have contributed significantly to the understanding of many cultures, have been widely applied. It is often assumed that the cultures these theories are based upon are similar to many archaeologically defined societies (Trigger 1990:13). Clearly, the conception of normal sociocultural development needs to be revised. In an attempt to avoid teleological models of social development, heterarchy may be employed as an alternative interpretive tool. Many of the models of sociopolitical organization can be seen to view societies as either egalitarian or ranked. In the latter, there is an implied permanence in positions of power, the idea that power flows only in one direction. There is also an implication that societies will develop in a predetermined way from egalitarian to hierarchical.

Heterarchy is a model in which the constituent parts of a social construct may be viewed in a number of ways. Heterarchical theory attempts to stress the fluidity of human interaction and social relationships. The model serves as a reminder that "interactive elements in complex systems need not be permanently ranked relative to one another" (Crumley in press). It is an essentially contextual model that relies on an understanding of the ephemeral nature of all human interactions. This paradigm provides a degree of flexibility for explanatory models of social evolution. Assuming the presence and permanence of rank is problematic. This is evident when one considers the complexity of social relationships that have spatial, temporal, and biological dimensions. Crumley $(1995: 2)$ believes that the 
concept of hierarchy has come to be used interchangeably with order and has, as a result, "disproportionately influenced theory building in both social and natural scientific contexts."

Heterarchy may also be found in hierarchical societies but it may not be the dominant factor. As Crumley (in press) asserts, "all state systems have some heterarchical elements, just as all egalitarian societies have some relations that are hierarchical (e.g., age)." Heterarchy is a model in which power relationships are constantly changing in time and space. It is the task of the archaeologist to assess whether archaeological evidence indicates the predominance of hierarchy or heterarchy. Status and social differentiation in a heterarchic system may be thought of as "a flexible, complex, multifaceted, multilateral system" (White 1995:111). Personal and family wealth, social function, and kinship rank, may have operated simultaneously creating multidimensional pathways toward social status in which wealth played only one part (White 1995:111). The heterarchical model allows the investigator to view evidence differently. The presence of differentially wealthy interments in a cemetery may be interpreted as a proclivity of prehistoric societies to recognize an individual's social, ritual, or economic role (White 1995). Applying traditional models, such evidence may suggest a system of achieved status but a heterarchical perspective allows us to consider ancillary factors such as those above.

\section{RECENT INTERPRETATIONS OF THE BRONZE AGE}

\section{Social Stress}

The Bronze Age of Southeast Asia is poorly understood, especially the nature of the social structure and the appearance of indigenously produced copper alloys (cf. Bayard 1980, 1984; Glover 1991; Higham 1984, 1989; Hutterer 1991; Kennedy 1977; Pautreau et al. 1997; Solheim 1968; Vallibhotama 1991). In some areas, this period appears to have been characterized by conflict, while in others, evidence is fugitive. Indications of warfare, in the form of weaponry, increases as the Bronze Age progresses, especially in Vietnam and Southern China (Higham 1996:96, 100), while White (1982:45-49) has proposed that the Bronze Age in Thailand was a relatively peaceful period. White argues that intercommunity conflict was reduced because access to resources was not circumscribed. She believes that unrestricted access to raw materials, such as salt and copper ore, made it difficult for any particular community to establish and maintain a dominant position in Bronze Age society. This is not to say that hierarchy did not exist during General period B but this form of social organization does not appear to have had lasting significance, in that evidence for it is largely absent in Bronze Age cemeteries.

\section{Mode of Production}

Although many sites in Thailand share a similar inventory of imported artifacts, it is possible to identify localized pottery traditions (Wilen 1992:109). White (1995: 105) believes that Bronze Age Thailand was populated by individual, culturally localized, autonomous communities. It is apparent, based upon the finds of burnishing stones and anvils, that villages produced their own ceramics resulting in regional variation. 


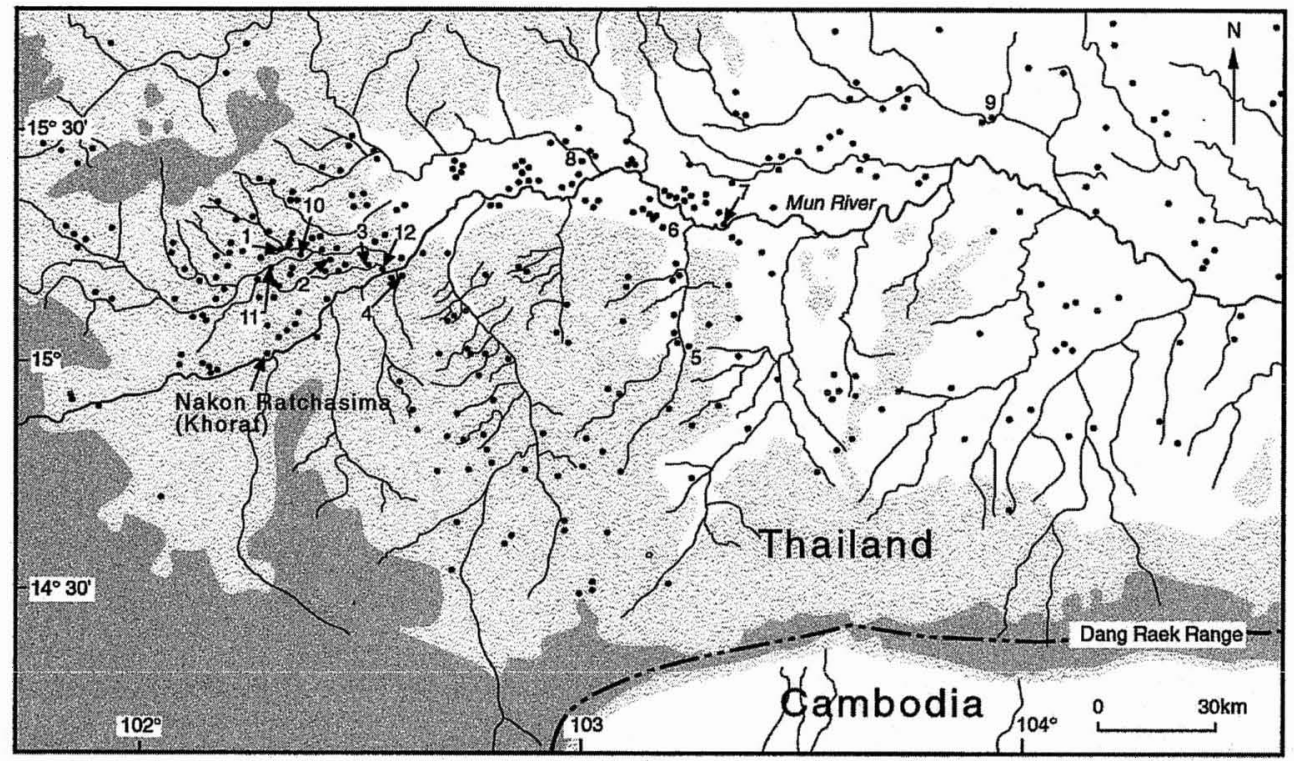

Land above 170m Land above 250m . Archaeological site _...- International Border

Fig. 1. The Mun River Valley showing sites mentioned in the text (after Higham n.d.). 1: Noen U-Loke; 2: Ban Prasat; 3: Ban Tamyae; 4: Phimai/Ban Suai; 5: Ban Takhong; 6: Ban Don Phlong; 7: Non Yang; 8: Non Krabuang; 9: Non Dua; 10: Ban Lum Khao (unmoated); 11: Non Muang Kao; 12: Non Ban Kham.

White and Pigott (1996:157), referring to copper mining and bronze production, state that "several lines of archaeological evidence support the view that production organization was characterized by independent specialists." This evidence includes small-scale production, absence of permanent villages exploiting raw materials, seasonal production, and a "differentiated production and distribution system" (White and Pigott 1996:158).

The data from Bronze Age sites in Thailand do not accord well with many traditional theoretical models of sociopolitical organization including the templates of tribe, band, or chiefdom. Higham (1989:187-188) has proposed that General period B settlements were most likely autonomous units comprising no more than 500 individuals. Within these villages he notes that "the attainment of status was flexible rather than fixed [and that] the relative position of each autonomous settlement was given to fluctuation and, therefore, instability." White (1995) has presented a similar picture of Bronze Age social organization in Thailand. She has taken the argument a step further, interpreting the evidence from a heterarchical perspective, a paradigm that differs from the often inflexible models of social organization normally applied to archaeological societies. In General period B cemeteries, there appears to be social differentiation based upon age, sex, and social and economic roles but no elite class (White and Pigott 1996:157).

Our understanding of the Bronze Age on the Khorat Plateau has been enhanced by the excavation and analysis of Ban Lum Khao (Fig. 1) in the Mun River Valley. The village of Ban Lum Khao $\left(15^{\circ} 14^{\prime} \mathrm{N}, 102^{\circ} 20^{\prime} \mathrm{E}\right)$ is situated on a 
Table 2. The Radiocarbon Dates from Ban Lum Khao (BlK), Non Muang Kao (NMK) Processed at the Radiocarbon Laboratory, University of Waikato, New Zealand

\begin{tabular}{lccccc}
\hline CODE & WK & DC13 & \% MODERN & RESULT BP & \multicolumn{1}{c}{ CALIBRATED } \\
\hline BLK 258 & 4507 & $-26.9 \pm 0.2$ & $68.2 \pm 0.4$ & $3080 \pm 50$ & 1435-1209 B.C. \\
BLK 293 & 4508 & $-27.0 \pm 0.2$ & $68.8 \pm 0.4$ & $3010 \pm 60$ & $1394-1068$ B.C. \\
BLK 287 & 4509 & $-25.7 \pm 0.2$ & $68.9 \pm 0.6$ & $3010 \pm 60$ & $1410-1068$ B.C. \\
BLK 207 & 4510 & $-24.0 \pm 2.0$ & $68.9 \pm 0.6$ & $3000 \pm 80$ & $1449-1019$ B.C. \\
BLK 160 & 4511 & $-25.9 \pm 0.2$ & $67.8 \pm 0.4$ & $3120 \pm 50$ & 1461-1255 B.C. \\
NMK 32 & 4512 & $-26.9 \pm 0.2$ & $80.4 \pm 1.6$ & $1750 \pm 160$ & 3 B.C. - A.D. 639 \\
NMK 81 & 4513 & $-24.0 \pm 2.0$ & N. A. & $1640 \pm 70$ & A.D. 315-584 \\
NMK 66 & 4514 & $-25.3 \pm 0.2$ & $80.9 \pm 0.9$ & $1700 \pm 90$ & A.D. 129-545 \\
NMK 32 & 4515 & $-26.2 \pm 0.2$ & $81.9 \pm 0.6$ & $1610 \pm 60$ & A.D. 336-600 \\
NMK 10 & 5872 & $-27.1 \pm 0.2$ & $79.8 \pm 0.5$ & $1810 \pm 60$ & A.D. 79-391 \\
NMK 15 & 5873 & $-27.3 \pm 0.2$ & $80.3 \pm 0.7$ & $1760 \pm 70$ & A.D. 118-428 \\
NMK 16 & 5870 & $-24.2 \pm 0.2$ & $79.6 \pm 1.0$ & $1840 \pm 110$ & 45 B.C. - A.D. 428 \\
\hline
\end{tabular}

Note: The ceramics from the upper and surface layers of Non Muang Kao may be attributed to the early Historic period. No suitable material from these layers was recovered for radiometric dating.

prehistoric site, which was initially occupied c. 1400 B.c. (Table 2). The site is located near the confluence of the Laem Tam Prasat and Laem Tam Kla streams. Higham and Thosarat excavated Ban Lum Khao in 1995-96, uncovering an area of 14.5 by $10 \mathrm{~m}$. The natural substrate was reached at a depth of $1.7 \mathrm{~m}$. The cultural deposits comprised three layers, the lowest of which contained evidence of the earliest occupation of the site. The middle layer incorporated the majority of the burials, distributed in a patterned manner. The cemetery included 112 males, females, children, and infants younger than five years, most of whom were orientated on a north-west axis, with the head to the southeast. The adult and children's burials were supine but some of the infants were interred in lidded burial jars, greater than $50 \mathrm{~cm}$ in diameter, often in association with smaller ceramic vessels and ornaments. Over 500 complete pottery vessels were recovered from the burials. Several of the pot forms are virtually identical to those recovered during the Fine Arts Department excavations at Ban Prasat (Monkhonkamnuanket 1992). The graves contained not only ceramics but also bangles of marble and shell, faunal remains, tools, and other items of jewelry. The uppermost deposit may be attributed to occupation activities that commenced after the use of the area as a cemetery ceased.

In an attempt to assess the nature of the social organization represented in the Ban Lum Khao cemetery, the material, chronological, and human dimensions have been analyzed (O’Reilly 1999). Four mortuary phases were identified at Ban Lum Khao (Fig. 2). The analysis of the Ban Lum Khao cemetery revealed similarities with other Bronze Age cemeteries such as Ban Na Di and Non Nok Tha (O'Reilly 1999). Broadly contemporaneous sites in Thailand, such as Ban Lum Kao, Non Nok Tha, Ban Na Di, and the earlier, Khok Phanom Di, share a widely related mortuary tradition. In all of these, the quantity and range of associated grave goods cut across age and sex boundaries. There appears to be a continuum in the burials from poor to wealthy. Often it is difficult to distinguish any definitive social divisions demarcated by wealth or symbols. Similarly, there is scant 
Mortuary phase one

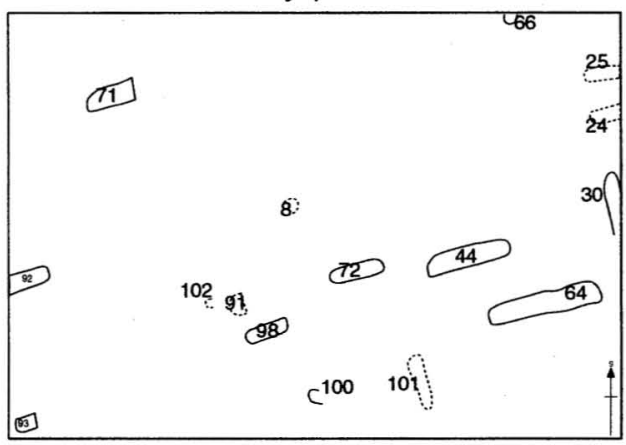

Mortuary phase three
Mortuary phase two (transitional)

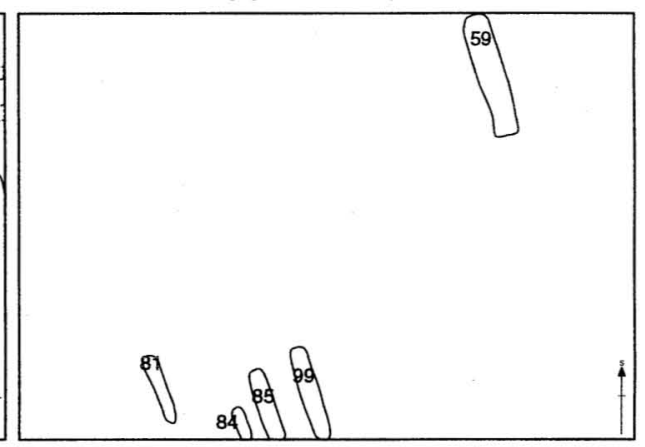

Mortuary phase four

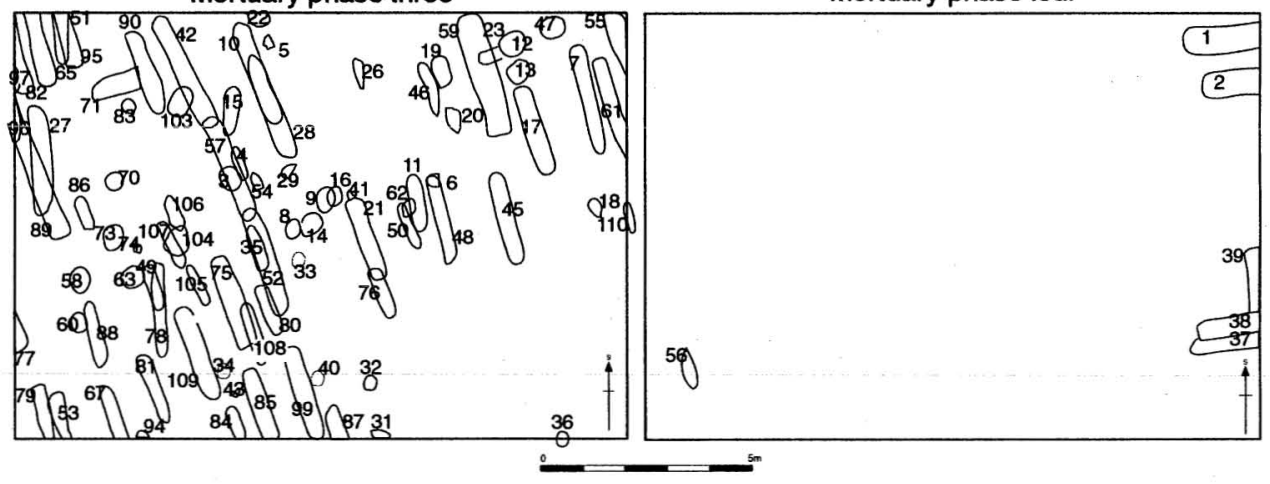

Fig. 2. The mortuary phases within the cemetery at Ban Lum Khao, Thailand.

evidence of elite control of resources or craft production and consequently, no evidence of control over distribution. In short, the evidence from these sites conforms to the models of social organization proposed by Higham (1989) and White and Pigott (1996).

\section{RECENT INTERPRETATIONS OF THE IRON AGE}

Wolters (1999:124), who cites evidence for heterarchy in modern Southeast Asia, states that the evidence for change from the heterarchic communities described above "would need to be substantial and convincing." The evidence from Iron Age sites, excavated as part of the Origins of Angkor Archaeological Project, is just that. These data indicate that there were profound changes in the social, political, and economic structure of society in Thailand and seem to suggest that hierarchically structured social systems developed, and/or had a more lasting impact. Prior to considering the evidence from the latest excavations on the Khorat Plateau, let us review the situation as it stands.

\section{Social Stress}

There are a number of indications that social stress increased during General period C. The number of Iron Age cemeteries excavated to date is limited but it 
is apparent that the inclusion of weaponry in burials is more common than it was during the preceding period. Sørensen's (1973:155-159) excavations at Tham Ongbah revealed individuals buried with lances, spearheads, halberds, and projectile points. More recently, excavations at Ban Wang $\mathrm{Hi}$ in northern Thailand have exposed graves containing decorated swords and large spears, thought, by the excavators, to have been used in warfare (Pautreau and Mornais 1998:12). Along with weaponry we may consider the morphology of Iron Age sites. While it would be imprudent to suggest that the appearance of sites ringed with moats is indicative of fortification, it is possible that a large fenced ditch near the center of Non Yang, in the Mun River Valley, is related to defense (Nitta 1991:6).

\section{Population Aggregation}

There is evidence that population aggregation started to develop in northeast Thailand during the Iron Age. In the Mun and Chi river basins, some sites grew very large and Higham (1989:219) estimates that settlements such as Non Chai and Ban Chiang Hian would have accommodated 1000 and 2000 people respectively. There is some indication that there was a movement onto agriculturally marginal land in the Mun River Valley (Moore 1986; Welch and McNeill 1991). Site density was also high during the Iron Age in the Huay Sai Khao Basin (Wilen 1987:107-110). Increasing population has been posited as a causative factor in the development of hierarchies (Johnson 1982) and analysis of settlement pattern has led Welch $(1984: 184)$ to suggest that social organization during the Iron Age was probably at the level of complex chiefdom in the Phimai region.

\section{Labor Organization}

Iron Age sites on the Khorat Plateau are notable for their encircling moats. Although we are unsure what the purpose of the moats was, it is clear that a great deal of effort was expended in their construction. The moats and reservoir at Ban Chiang Hian are estimated to have taken 500 adults one year to dig (Chantaratiyakan 1984 in Higham 1989:21). It could be argued that such a large mobilization of people would require a centralized societal structure (Wittfogel 1957), evidence of which is hinted at in Iron Age cemeteries.

The structure and content of cemeteries seem to have altered during the Iron Age. Sites such as Non $\mathrm{Pa}$ Kluay tend to contain a greater number and wider variety of items. Exotic items, including glass and carnelian beads are common, as are metal items of value (Wilen 1992:106).

The accumulated weight of this evidence seems to indicate that there was a shift from nonhierarchic sociopolitical relationships to those which may have been more stratified and enduring. The excavation of Non Muang Kao and Noen U-Loke, in the Mun River Valley, enhance our conceptions of the Iron Age in this area. The data from these sites confirm the suggestion that there was a move away from unranked social organization c. 500 B.C.

\section{NEW EVIDENCE FOR IRON AGE SOCIAL ORGANIZATION}

\section{Non Muang Kao}

Non Muang Kao, which comprises two discrete mounds, covers 55 ha. The site was occupied from around the beginning of the first century A.D. and abandoned 


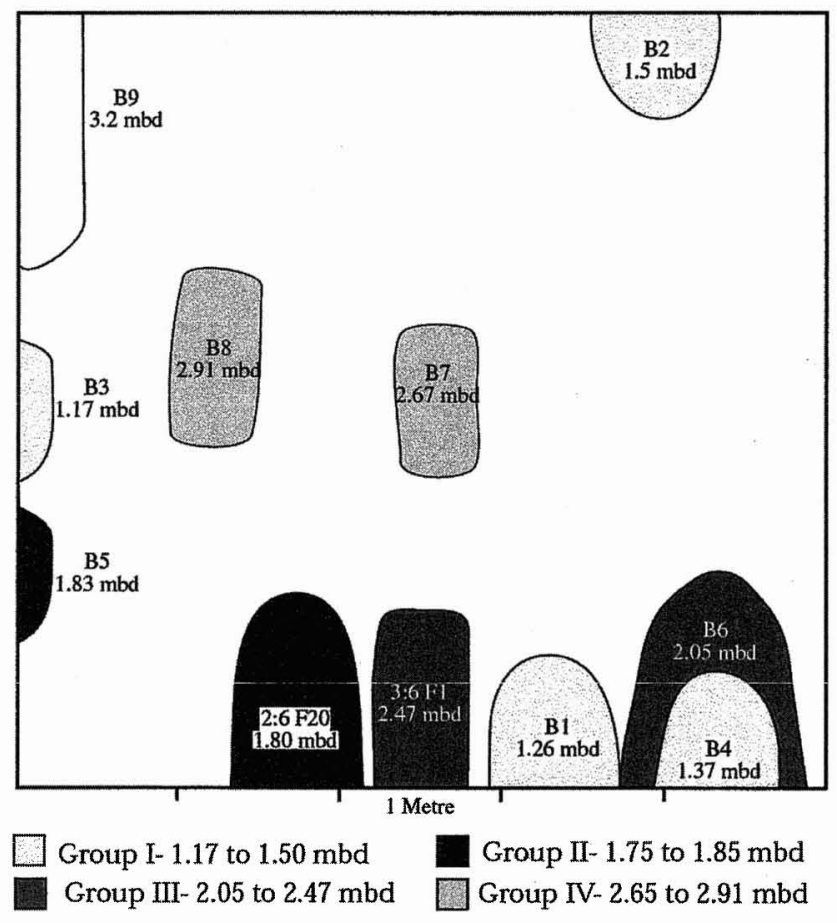

$\square$ Group V- $3.20 \mathrm{mbd}$

Fig. 3. Distribution of burials at Non Muang Kao illustrating the five different phases of the burials.

during the early Historic period (see Table 2). Non Muang Kao was probably selected for settlement due to the presence of a natural mound, in close proximity to a river. Such a location would have afforded the occupants protection from floodwater and enemies, as well as providing access to major trade and communication routes.

It is apparent that the $5 \mathrm{~m}^{2}$ area excavated saw a variety of uses including habitation, industrial activity, and disposal of the dead (O'Reilly 1997). Eleven mortuary contexts were identified which appear to comprise five phases (Fig. 3). All but one of the graves are orientated on a north-south axis, suggesting a degree of continuity in burial practice. The phases are discernible through an examination of the method of interment and stratigraphic position. Several burials above $2.5 \mathrm{~m}$ below datum were enveloped in a layer of white clay, most containing evidence of large quantities of rice. Burials below this level were not clay lined but did contain rice. There is also a recurring grave assemblage of shallow, streak burnished, Phimai black bowls, potsherds, and bronze artifacts such as bangles.

The limited excavations at Non Muang Kao have not provided a large enough sample for reliable statistical analysis. Nevertheless, a number of important and interesting differences between the burial population from the Bronze Age site of Ban Lum Khao and Non Muang Kao are intuitively apparent. Perhaps the most striking is the amount and range of grave goods found at Non Muang Kao. Several categories of artifact are not found at Ban Lum Khao, such as bimetallic 
Table 3. Presence and Absence of Artifact Categories at the Iron Age Sites, Noen U-Loke and Non Muang Kao and the Bronze Age Site Ban Lum Khao

\begin{tabular}{ll}
\hline ARTIFACT & \multicolumn{1}{c}{ LOCATION } \\
\hline Glass & Non Muang Kao/Noen U-Loke \\
Gold/gilded jewelry & Noen U-Loke \\
Bimetallic jewelry & Non Muang Kao/Noen U-Loke \\
Bronze jewelry & Non Muang Kao/Noen U-Loke \\
Iron sickles & Noen U-Loke \\
Tridacna bangles & Ban Lum Khao \\
Marble bangles & Ban Lum Khao \\
Carnelian/agate & Non Muang Kao/Noen U-Loke \\
Iron knives & Noen U-Loke \\
\hline
\end{tabular}

Note: Although no bronze artifacts were found in burials at Ban Lum Khao, fragments were found during the excavation.

jewelry, iron tools, semiprecious stones, and precious metals (Table 3). These items evidence technological advances and the possible expansion of trade networks that occurred after the Bronze Age. Bronze is commonly encountered in the graves from Non Muang Kao, fashioned into rings, spirals, and bells, often evidencing a high degree of technical skill. Iron is also present at the site, tools are found outside of mortuary contexts, and iron is often combined with bronze to make jewelry found in graves. Another interesting and important change occurs in the ceramic assemblage. All the interments at Non Muang Kao contain ceramics that are part of a large, regional pottery complex. It is likely that these vessels were produced off-site, as no evidence for ceramic production was encountered during the excavation of the site.

\section{Noen U-Loke}

Excavations at a site less than $20 \mathrm{~km}$ from Non Muang Kao were undertaken by Higham and Thosarat in 1997-1998. Although it is believed that occupation of Noen U-Loke commenced during General period B, nearly the whole sequence belongs to the ensuing period (Higham and Thosarat 1998:151). Although the analysis of Noen U-Loke is in progress, it is possible to draw some pertinent information from the available data. Several factors are of interest, including evidence of significant disparity between interments. Some individuals have no grave goods while others are adorned with many bronze bangles, rings, and necklaces made of semiprecious stones and precious metals (Higham 1998:7-9). The appearance of iron knives and spears is another notable feature at Noen U-Loke. The nucleation of burials is clear (Fig. 4). Several burial clusters include an outstandingly rich individual and seem to have "recurrent singular characteristics" (Higham 1998:8). Statistical analysis has revealed a greater degree of clustering at Noen U-Loke than at Ban Lum Khao or another Bronze Age site, Non Nok Tha (McCaw 1998).

The technical skill involved in the production of bronzes has been mentioned. Many items encountered at Noen U-Loke were made using the cire-perdu method (Higham 1998). The bimetallic jewelry, found at both Non Muang Kao and 


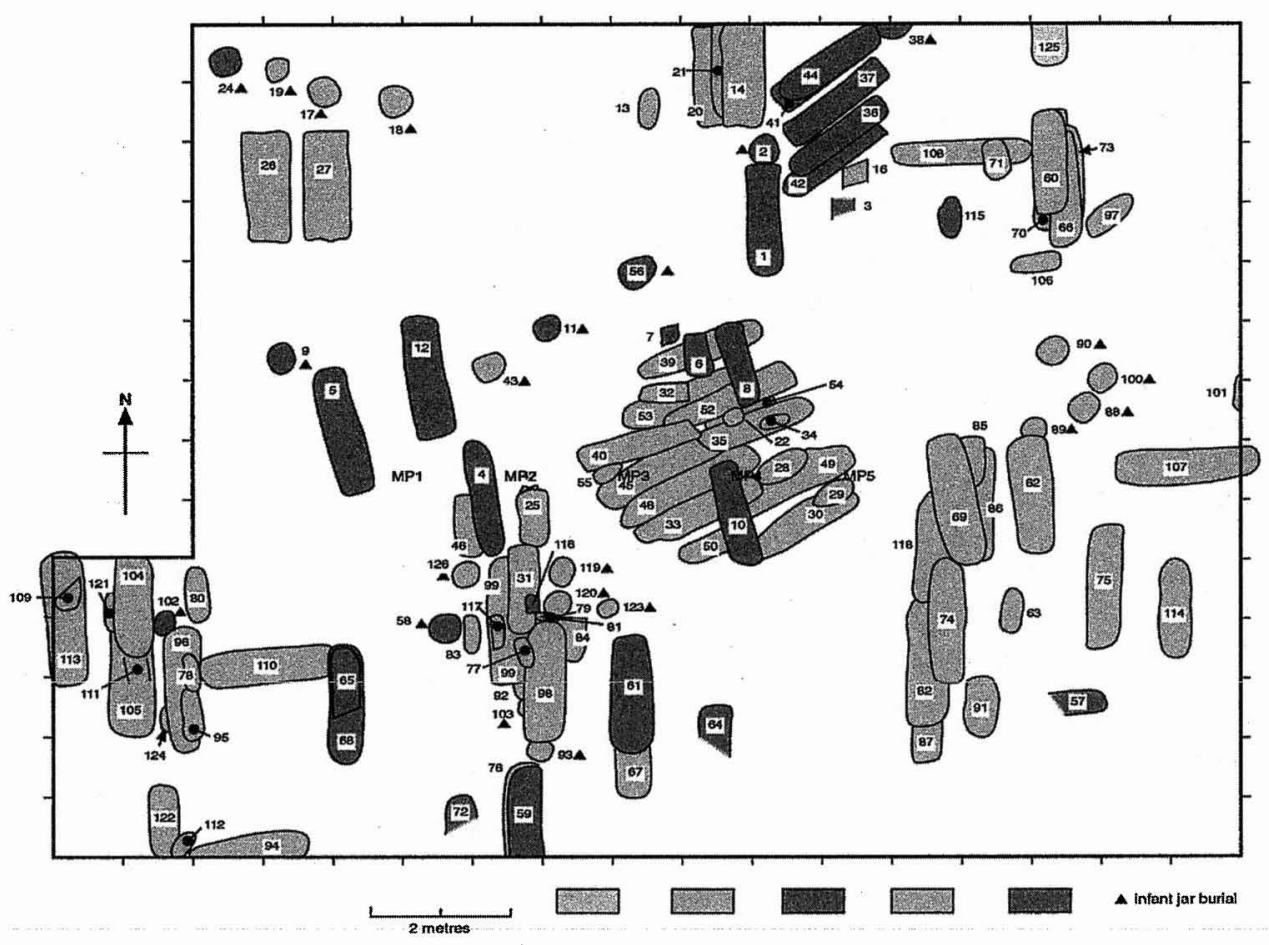

Fig. 4. Plan of the cemetery at Noen U-Loke (after Higham and Thosarat 1998).

Noen U-Loke (Higham 1998:8; O’Reilly 1997:141), indicates enhanced technical expertise as does the presence of gilded jewelry at Noen U-Loke (Higham 1998:8). The metal artifacts recovered during the excavation of Ban $\mathrm{Na} \mathrm{Di}$ and Non Chai (Phase IV) may, similarly, indicate increased specialization in the Iron Age (Higham 1989:219). There is also some indication that glass may have been manufactured or reworked during this period (Higham 1998:5).

\section{DISCUSSION}

The identification of Iron Age sites in the upper Mun River Valley is facilitated by the ubiquity of Phimai black pottery (Solheim 1965; Welch 1985; Welch and McNeill 1988). This instantly recognizable horizon marker represents the most obvious indication of the temporal placement of a prehistoric site. The advent of this ceramic form seems to herald other changes in the prehistoric society of the Mun Valley and is an appropriate place to begin an examination of these phenomena.

\section{Ceramic Production}

It has been argued that General period B is characterized, in many parts of Thailand, by apparently localized ceramic and other craft traditions (White 1995; White and Piggot 1996). As we have seen, the production of pottery at Ban Lum Khao also appears to have been undertaken at the local level. Sometime after 
c. 500 B.C. there is an apparent shift in the mode of ceramic production in the upper Mun Valley. Standardized vessels begin to appear at this time. These have come to be called Phimai black ceramics and the characteristic color and thinwalled construction are unmistakable. It is unlikely that these were produced at the household level in every community, judging from the evident decrease in artifacts associated with pottery production found at sites associated with the vessel form.

There are no anvils or burnishing stones found in mortuary contexts at Non Muang Kao. Only two possible burnishing stones and four anvils were found at Noen U-Loke. A lack of pottery production tools is notable at other Iron Age sites, outside of the field of distribution of Phimai black, including Ban Don Ta Phet or Ban Wang Hi (Glover et al. 1984; Pautreau et al. 1997). According to Stein $(1998: 20)$, the specialized manufacture of ceramics may be determined by an examination of the degree of standardization. Specialist-produced utilitarian goods demonstrate a higher degree of standardization than goods produced at the household level. The uniformity of the Phimai black style over a large area certainly conforms to this characterization of specialist-produced goods.

A shift in the mode of production is important when considering the political and social structure of prehistoric society. There are a number of possible explanations for the evidence concerning ceramic production. Ceramic production may have been centralized or the apparent standardization may result from emulation of a particular style, perhaps from a particularly powerful or wealthy center. Alternatively, one or several small villages may have become the sole suppliers of ceramics for the region. Any of these explanations of the shift in ceramic production represents a major change in the lifeways of the people of the area and is indicative of cultural change. Rice $(1981,1991)$ believes that the development of mass-produced utilitarian crafts is often linked to the evolution of state societies. This has been suggested by MacDonald (1980) with reference to northeast Thailand. The mass production of pottery at presently unidentified centers may signal increased specialization and regionalization by a political entity. It should be note, however, that a mineralogical analysis of Phimai black pottery from Ban Tamyae did not seem to indicate uniformity in production technique (Welch and McNeill 1988).

\section{Mortuary Ritual}

The shift in ceramic production is not the only difference evident between General period B and General period C in the Mun River Valley. There is, as we have seen, a significant increase in mortuary differentiation. Iron Age burials on the Khorat Plateau demonstrate a range of variation not encountered in the graves at Ban Lum Khao or Bronze Age Ban Prasat (Monkhonkamnuanket 1992; O'Reilly 1999). The range of grave goods is also notably increased, with a wider variety of materials being used. These include glass, iron, combinations of iron and bronze, and semiprecious stones such as agate and carnelian. It may be assumed that the greater skill needed to produce the elaborate grave goods required a greater investment of time. Whether part-time seasonal craftspeople would possess the complex skills necessary to create bimetallic jewelry is debatable. Based on present evidence, it appears that there was an increase in craft specialization during the Iron Age (Higham 1996:330, 1998:140). 
It has been noted that the burials at Noen U-Loke appear, during most mortuary periods, to be clustered. One possible explanation of this is the increase in importance of consanguine relationships. Hierarchically organized entities often stress the importance of kinship, especially in their nascent stage. This dimension is often reflected in mortuary patterns (Wason 1994:48) where groups of wealthy graves are found to cluster. All of these factors are indicative of an altered sociopolitical climate in the Mun River Valley.

\section{Demography}

There are also indications of demographic change in northeast Thailand, specifically the apparent proliferation of sites dating to the Iron Age. It is possible that the increase in size and frequency of sites is indicative of population increase, a factor often accompanied by competition over resources. Identifying these resources is a complex task. Rivett (1999:111) notes that sites are chosen based on a consideration of the environment as a whole. Settlement sites, he believes, were selected based on the location of vegetation, water, soils, and natural deposits of minerals rather than one of these factors in particular. Although there are many factors that seem to influence site location, salt seems to have played a significant role in the structure of prehistoric settlement patterns (Rivett 1999:94).

\section{Environment}

The morphology of many Iron Age sites has been noted and has been the source of much debate. Iron Age mounds are readily apparent with their encircling moats. There are indications that these moats may represent ancient riverbeds, which may have been engineered to surround many sites (Boyd 1997). The possibility that the moats served a defensive purpose has been entertained (Moore $1986: 205)$ and this is a plausible explanation, although the threat may have been posed by the environment.

According to Nutalaya et al. (1988) the Mun and Chi rivers carried excessive discharges during the period $2270 \pm 70$ to $1650 \pm 90$ years B.P., a period coincident with the Iron Age in Thailand. Evidence from China and Denmark offer insights into the climatic regimen during the Iron Age in Thailand. Han Dynasty annals report crop losses, rain, and cold weather from 207-205 B.C. (Anderson 1987:12). This type of climate appears to have had a global effect. Evidence from Danish bogs indicates an abnormal amount of rain during this time in northern Europe (Anderson 1987:12) and $5 \mathrm{~m}$ of sediment appears to have been deposited at Ban Non Chai during the same period (Nutalaya et al. 1988:112).

It is possible that the moats around the Iron Age sites were constructed as part of a flood defense. The proliferation of Iron Age sites on the agriculturally marginal "higher terraces" noted by Moore (1988:121) may represent an attempt to escape flood-prone valleys. A systematic investigation of the chronology of sites, located in the flood plain and upper terrace, needs to be conducted to confirm this hypothesis. Environmental stress may have contributed to an increase in centralized control and a development of hierarchical structures. It is the presence of these features that may be indicative of increasing political centralization in Iron 
Age communities. The excavation of large ditches to manipulate riverine environments would have required careful engineering and a substantial work force, possibly under centralized control.

\section{Developments c. 500 B.C.}

The coincident appearance of iron in artifact assemblages in prehistoric sites and evidence for social changes has not gone unnoticed. Bronson $(1985: 1)$ has noted that "[t]he appearance of iron ... seems to be accompanied in some parts of [Thailand] by significant alterations of the societies and economies involved." It is difficult to establish a causative relationship between the inception of the new technology and the apparent alterations in the social fabric. The role of iron in the evolution of the prehistoric societies on the Khorat Plateau begs further examination. It would appear that during the Iron Age, the Mun River Valley saw a proliferation of habitation sites and an increase in public labor efforts. There also seems to have been a centralization of ceramic production, represented by Phimai tradition pottery, and an increase in craft specialization.

An increase in the number of agricultural tools found in mortuary contexts in Thailand may be indicative of changes in agricultural practice during the Iron Age. Evidence of an agricultural surplus is difficult to establish but the abundance of rice in many interments may indicate that such a surplus existed (Higham 1998; O'Reilly 1997). Long-distance trade appears to increase during this period, as a wide range of exotic stones and metals are found in burials. The location of many Iron Age sites on waterways is also suggestive that control of trade and communication may have been exercised. The proliferation of small mounds, created in the extraction of salt, is testament to the importance of this resource in the Mun River Valley. Certainly, Indian traders seeking aromatic woods and fragrant resins were lured to the region at a time when these sites would have been occupied, thus increasing competition among the indigenous population (Coedès 1968: 19).

The reasons for the erosion of the apparently unstratified system, evident during the Bronze Age in the Mun River Valley, are difficult to assess based on present evidence. It is, however, possible to advance a number of possibilities that may have contributed to the shift to a more hierarchical dynamic. White $(1995: 112)$ has suggested that the shift occurred as a response to stressful environmental variability, an idea first advanced by Welch and McNeil (1991). This proposal can be understood from a perspective in which humans interact with their environment and adapt to alterations in it. Stressful environmental variability is an attractive proposition if one considers the evidence of massive weather disturbances proposed by Nutalaya et al. (1988). Catastrophic floods during the second century B.C. may explain the presence of the channels found around Iron Age sites. It is possible that these were constructed in an attempt to control flooding. Assuming the channels were dug over a short period, such projects would have required a substantial work force. It may be argued that the direction and control necessary to construct these channels was a catalyst or at least a symptom of hierarchical social systems.

There is a notable increase in the amount of exotic material culture during the Iron Age in the Mun River Valley. An alternative explanation or contributing 
factor in the development of hierarchical structures may be found in an examination of control of exchange routes or export commodities. The location of settlements on river systems may have been crucial to control upstream and downstream interaction. A corollary of the importance of site location may be the construction of the channels that would offset flooding, a more favorable alternative than relocation. It is also possible that competition over access to exotic exchange items developed during the Iron Age, evidenced by the increase in military paraphernalia found in interments (Higham and Thosarat 1998; Pautreau and Mornais 1998; Sørensen 1973; Wilen 1987).

\section{CONCLUSION}

It has been noted that Bronze Age societies in Southeast Asia do not follow the pattern established when bronze technology was introduced elsewhere. This region appears to be an exception to the rule, that the appearance of bronze and the rise of urbanism are coincident. In most other parts of the world, the introduction of bronze technology is associated with social, political, and economic developments that signal the "rise of the state." It is only in Southeast Asia that such developments are not in evidence (Muhly 1988:16).

Only later, with the advent of iron technology, do aspects of hierarchization begin to appear and become entrenched in the prehistoric cemeteries of Thailand. Whether the discovery of the necessary technology to produce this metal was the catalyst is unknown but there are indications that it played a significant role in the alteration of societies after c. 500 в.C. The moats encircling these sites may indicate significant environmental stress, a factor that may also have played a part in transforming the sociopolitical landscape.

The excavation and analysis of the mortuary remains at Ban Lum Khao has resulted in a hitherto undocumented understanding of the sociopolitical organization in the Mun River Valley after c. 1400 B.C. (O'Reilly 1999). The research conducted at Non Muang Kao has, similarly, contributed to our understanding of life during the Iron Age in the area (O'Reilly 1997, 1999). Evidence from this site has, in conjunction with that from Noen U-Loke (Higham and Thosarat 1998), demonstrated significant changes in the sociopolitical organization of the peoples who lived in the area. It appears that many aspects of the heterarchical system, present during the Bronze Age, were eroded in the Iron Age. There is growing evidence of an entrenched hierarchical organization. This apparent alteration in social order, after the Bronze Age, is of profound interest. It is hoped that a greater understanding of these changes will be achieved with the completion of the analysis of Noen U-Loke.

There are a number of factors that may have contributed to a shift in the social dynamic in General period C and the role of each needs to be explored. As it stands it is apparent that the appearance of iron technology may correspond to an increase in production and possibly agricultural surplus. There are also indications that there was an increase in population during the Iron Age. The location of population, with regard to resources, is little understood but salt may have played a major role. Increased competition and possibly social stress, evident in an increase in weaponry in General period C burials, are possible results of a larger population and limited resources. 
Heterarchical theory is a useful tool in understanding the development of culture prior to the Iron Age in Southeast Asia. The evidence presently available tends to indicate that there was an erosion of the heterarchical dynamic with a shift toward more entrenched hierarchical controls. It is possible that elements of heterarchy persisted into the Iron Age but this hypothesis can only be confirmed through further research. Hierarchies resting on a foundation of heterarchical dynamics may help to explain the unique development found in later Southeast Asian polities, polities which refused to be dominated by alien cultures yet embraced many of their positive aspects.

\section{ACKNOWLEDGMENTS}

I would like to take this opportunity to thank Professor Charles Higham and Dr. Ratchanie Thosarat for their support. I also thank Miriam Stark, Teresa Smith, Bec Connolly, James Chetwin, Richard Walter, and Sarah Talbot for their editorial assistance, and Jeremy Habberfield-Short for his suggestions. Any errors are my responsibility.

\section{REFERENCES}

ANDERson, I.

1987 Volcanic eruption led to mass starvation. New Scientist 116 (1591):12.

BAYARD, DONN

1976 A Course Toward What? Evolution, Development and Change at Non Nok Tha, Thailand. Ph.D. diss. University of Hawai $\mathrm{i}$, Honolulu.

1980 An Early Indigenous Bronze Technology in Northeastern Thailand; Its Implications for the Prehistory of East Asia, in The Diffusion of Material Culture: 191-214, ed. H. LoofsWissowa. Honolulu: SSRI.

1984 A tentative regional phase chronology for northeast Thailand, in Southeast Asian Archaeology at the XV Pacific Science Congress 16:161-168, ed. D. Bayard. Dunedin: Otago University Studies in Prehistoric Anthropology.

1992 Models, scenarios, variables and suppositions: Approaches to the rise of social complexity in mainland Southeast Asia, 700 B.C.-A.D. 500, in Early Metallurgy, Trade and Urban Centers in Thailand and Southeast Asia: 13-38, ed. I. Glover, P. Suchitta, and J. Villiers. White Lotus.

1996 Bones of contention: The Non Nok Tha burials and the chronology and context of early Southeast Asian bronze, in Ancient Chinese and Southeast Asian Bronze Age Cultures, vol. 2, ed. N. Barnard and F. Bulbeck. Taiwan: Taipei Southern Material Center Inc.

BenNeTt, ANNA

1988 Prehistoric copper smelting in central Thailand, in Prehistoric Studies: The Stone and Metal Ages in Thailand: 125-135, ed. P. Charoenwongsa and B. Bronson. Bangkok: Thai Antiquity Working Group.

BOYd, WILLIAM

1997 The geoarchaeology of the prehistoric ditched sites of the upper Mae Nam Mun Valley northeast Thailand I: Floodplain palaeodrainage patterns derived from aerial photograph interpretation. Unpublished research paper.

Bronson, BenNET

1979 The late prehistory and early history of central Thailand with special reference to Chansen, in Early Southeast Asia: 315-337, ed. R. B. Smith and W. Watson. New York: Oxford University Press.

1985 Notes on the Iron Age in Thailand. Journal of the Siam Society 73(1): 205-225.

BRUMFIEL, Elizabeth

1995 Heterarchy and the analysis of complex societies: Comments, in Heterarchy and the Analysis of Complex Societies: 125-131, ed. R. Ehrenreich, C. Crumley, and J. Levy. Washington D.C.: American Anthropological Association. 
Chantaratiyakarn, Payom

1984 The Middle Chi research programme, in Prehistoric Investigations in Northeast Thailand: 565-643, ed. C.F.W. Higham and A. Kijngam. Oxford: British Archaeological Reports (International Series) 231.

Coedès, GeOrges

1968 The Indianised States of Southeast Asia. Honolulu: University of Hawai'i Press.

Crumley, Carole

1995 Heterarchy and the analysis of complex societies, in Heterarchy and the Analysis of Complex Societies: 1-6, ed. R. Ehrenreich, C. Crumley, and J. Levy. Washington D.C.: American Anthropological Association.

in press Three-winged Bird: Chaotic Strange Attractors and the Evolution of Sociopolitical Complexity, in Leaders to Rulers: The Development of Political Centralization, ed. Jonathan Haas. New York: Plenum Press.

FRIED, MORTON

1967 The Evolution of Political Society: An Essay in Political Anthropology. New York: Random House.

FRIEDMan, J., AND M. Rowlands, eds.

1977 The Evolution of Social Systems. London: Duckworth.

GLOVER, I.

1991 The Bronze-Iron Age in western Thailand. Paper presented at the conference The High Bronze Age of Southeast Asia and South China, Hua Hin, Thailand.

Glover, Ian C., Pisit Charoenwongsa, P. Alvey, and N. Kamnounket

1984 The cemetery of Ban Don Ta Phet, Thailand, results from the 1980-1 season, in South Asian Archaeology: 319-330, ed. B. A. Allchin and M. Sidell. Cambridge: Cambridge University Press.

Higham, Charles F. W.

1984 The Social Structure of the Ban Na Di Prehistoric Population, in Southeast Asian Archaeology at the XV Pacific Science Congress 16:72-85, ed. D. T. Bayard. Dunedin: University of Otago Studies in Prehistoric Anthropology.

1989 The Archaeology of Mainland Southeast Asia. Cambridge: Cambridge University Press.

1994 Chronometric hygiene and the Bronze Age of Southeast Asia. Unpublished paper read at the Congress of Indo-Pacific Prehistory Association, Chiang Mai, Thailand.

1996 The Bronze Age of Southeast Asia. Cambridge, Cambridge University Press.

1998 Noen U-Loke and the implications for the origins of early states. Paper presented at the 16th Congress of the Indo-Pacific Prehistory Association, Melaka, Malaysia.

Higham, Charles F. W., and Ratchanie Bannanurag

1990 The Excavation of Khok Phanom Di, a Prehistoric Site in Central Thailand, vol. I, The Excavation, Chronology, and Human Burials. Society of Antiquaries of London, Research Report No. 47. London.

Higham, Charles F. W., and Amphan Kijngam

1984 Prehistoric Investigations in Northeast Thailand. British Archaeological Reports International Series 231. Oxford.

Higham, C., AND R. Thosarat

1998 Thailand: From Prehistory to Sukhothai. Bangkok: River Books.

2000 The origins of the civilisation of Angkor. Antiquity 74:27-28.

Hutterer, K.

1991 The High Bronze Age in Southeast Asia: Introductory remarks. Paper presented at the Conference of the High Bronze Age of Southeast Asia and South China, Hua Hin, Thailand.

JoHnson, G.

1982 Organisational structure and scalar stress, in Theory and Explanation in Archaeology: 389421, ed. C. Renfrew, M. Rowlands, and B. Segraves. New York: Academic Press.

KENNEDY, J. I.

1977 From stage to development in prehistoric Thailand: An exploration of the origins of growth exchange and variability in Southeast Asia, in Economic Exchange and Social Interaction in Southeast Asia: Perspectives from Prehistory, History and Ethnography: 28-38, ed. K. L. Hutterer. Ann Arbor: Center for Southeast Asian Studies, University of Michigan. 
MACDONALD, W.

1980 Some Implications of Societal Complexity: Organizational Variability at Non Nok Tha, Thailand (2000-0 B.c.). Ph.D diss. University of Michigan, Ann Arbor.

MCCAW, MORAG

1998 The spatial analysis of prehistoric cemeteries in Thailand. Unpublished Bachelor of Arts (Honors). Department of Anthropology, Dunedin, University of Otago.

Monkhonkamnuanket, $\mathrm{N}$.

1992 Ban Prasat: An Archaeological Site. Fine Arts Department Thailand, Thailand.

\section{Moore, Elizabeth}

1986 Moated settlement in the Mun Basin, northeast Thailand, in Southeast Asian Archaeology 1986, 201-212, ed. I. Glover and E. Glover. British Archaeological Reports International Series 561. Oxford.

1988 Moated Sites in Early North East Thailand. British Archaeological Reports International Series 400. Oxford.

Muhty, J.

1988 The beginnings of metallurgy in the Old World, in The Beginnings of the Use of Metals and Alloys: 2-20, ed. R. Maddin. Cambridge, MA: M.I.T. Press.

NitTA, EijI

1991 Archaeological study on the ancient iron-smelting and salt-making industries in the northeast of Thailand. Preliminary report on the excavations of Non Yang and Ban Don Phlong. Journal of Southeast Asian Archaeology $11: 1-46$.

Nutalaya, Prinya, Wanchai Sophonsakularat, Manit Sonsuk, and Nawarat Wattanachai 1988 Catastrophic Flooding-An Agent for Landform Development of the Khorat Plateau: A Working Hypothesis. Proceedings of the Workshop on Correlation of Quaternary Successions in South, East and Southeast Asia, Bangkok, UNESCO.

O'Reilly, Dougald J. W.

1997 The discovery of clay-lined floors at an Iron Age site in Thailand; preliminary observations from Non Muang Kao, Nakon Ratchasima Province. Journal of the Siam Society $85(1): 1-14$.

1999 A Diachronic Analysis of Social Organization in the Mun River Valley. Ph.D. diss. Department of Anthropology, Dunedin, University of Otago.

Pautreau, J.-P., A. Matringhem, and P. Mornais

1997 Thailande, la fin des temps prehistoriques (in French). Archeologia 330.

Pautreau, J.-P., And P. Mornais

1998 Ban Wang Hi (Thailande) Travaux 1998. Journee Prehistorique et Protohistorique de Bretagne, Université de Rennes 1, unpublished paper (in French).

Rice, Prudence

1981 Evolution of specialized pottery production: A trial model. Current Anthropology 22 :219240.

1991 Specialization, standardization and diversity: A retrospective, in The Ceramic Legacy of Anna O. Shepard: 257-279, ed. R. Bishop and F. Lange. Niwot: University Press of Colorado.

RivetT, Paul

1999 Community landscapes in Northeast Thailand. Master's thesis. Department of Anthropology, Dunedin, University of Otago.

SaHLINS, Marshall

1958 Social Stratification in Polynesia. Seattle: University of Washington Press.

Service, Ellman

1962 Primitive Social Organization, an Evolutionary Perspective. New York: Random House.

Solheim, William

1965 A preliminary report on a new pottery complex in northeastern Thailand. Felicitation Volumes of Southeast Asian Studies 1:249-254.

1968 Early Bronze in Northeastern Thailand. Current Anthropology 9(1):59-62.

Sørensen, Per

1973 Prehistoric iron implements from Thailand. Asian Perspectives 16(2):134-173. 
STEIN, GIL

1998 Heterogeneity, power, and political economy: Some current research issues in the archaeology of Old World complex societies. Journal of Archaeological Research 6(1):1-45.

Trigger, B.

1990 A History of Archaeological Thought. Cambridge: Cambridge University Press.

VALLiBHOTAMA, S.

1991 Bronze-Iron Age foundations for the origin of the state of Chenla. Unpublished paper read at the Conference of the High Bronze Age, Hua Hin, Thailand.

WASON, PAUL

1994 The Archaeology of Rank. Cambridge: Cambridge University Press.

WEISS, ANDREW D.

1992 The social context of copper production in central Thailand: Evidence from mortuary and industrial data. Paper read at the 4th International Conference of the European Association of Southeast Asian Archaeologists, Rome, 28 September-4 October 1992.

\section{WELCH, DAVID}

1984 Settlement pattern as an indicator of socio-political complexity in the Phimai region, Thailand, in Southeast Asian Archaeology at the XV Pacific Science Congress: 129-152, ed. D. Bayard. Dunedin, New Zealand, University of Otago.

1985 Adaptation to Environmental Unpredictability: Intensive Agriculture and Regional Exchange at Late Prehistoric Centers in the Phimai Region in Thailand. Ph.D. diss. University of Hawai'i, Honolulu.

Welch, David, and Judith MCNeILl

1988 Excavations at Ban Tamyae and Non Ban Kham, Phimai Region, Northeast Thailand. Asian Perspectives 28(2): 99-123.

1991 Settlement, agriculture and population changes in the Phimai region, Thailand. Bulletin of the Indo-Pacific Prehistory Association 11:210-228.

White, JoYce C.

1982 The Discovery of a Lost Bronze Age, Ban Chiang. Philadelphia: University of Pennsylvania Press.

1995 Incorporating Heterarchy into Theory on Socio-Political Development: The Case from Southeast Asia, in Heterarchy and the Analysis of Complex Societies: Comments: 101-123, ed. R. Ehrenreich, C. Crumley, and J. Levy. Washington D.C.: American Anthropological Association.

White, Joyce, and Vincent Pigott

1996 From community craft to regional specialization: Intensification of copper production in pre-state Thailand, in Craft Specialization and Social Evolution: In Memory of V. Gordon Childe: 151-175, ed. B. Wailes. Philadelphia: The University Museum of Archaeology and Anthropology, University of Pennsylvania.

WILEN, RiCHARD

1987 Excavation and site survey in the Huay Sai Khao Basin, northeastern Thailand. Bulletin of the Indo-Pacific Prehistory Association 7:94-117.

1992 Mortuary traditions and cultural identity in the Khorat Plateau piedmont, northeast Thailand, in Southeast Asian Archaeology, 1990:103-110, ed. I. Glover. Hull: Center for South-East Asian Studies, University of Hull.

WITTFOGEL, KARI

1957 Oriental Despotism. A Study of Total Power. New Haven: Yale University Press.

Wolters, Oliver W.

1999 History, Culture, and Region in Southeast Asian Perspectives. Revised edition. Ithaca: Southeast Asia Program Publications.

\section{ABSTRACT}

The archaeological evidence of social groups in Thailand has long been noted for not conforming to the standard paradigms of social organization. This paper investigates the concept of heterarchy before turning to consider current conceptions of the Bronze and Iron Ages in Thailand. New evidence from a recently excavated 
site, Ban Lum Khao, is considered and evaluated in the context of the existing knowledge of the period. The current understanding of the Iron Age is also evaluated and enhanced through the incorporation of data from two sites in northeast Thailand, Non Muang Kao and Noen U-Loke. The paper concludes that the data from prehistoric Thailand are better interpreted from a heterarchical perspective. The possible causative factors of stratified social organization are considered from a heterarchical perspective, examining ceramic production, mortuary practice, demography, and environment. Keywords: Heterarchy, archaeology, Thailand, Bronze Age, Iron Age, hierarchy. 